For any position of the short mercury thread, the diameter is inversely proportional to the square root of the thread length.

$$
\frac{d_{1}}{d_{0}}=\sqrt{\frac{\lambda_{0}}{\lambda_{1}}}
$$

where $d_{0}$ is the average diameter of the capillary tube.

We may compute the percentage deviation of the diameter at any point from the average diameter from the equation

$$
D=100\left(\sqrt{\frac{\lambda_{0}}{\lambda}}-1\right)
$$

in which

$$
\begin{aligned}
D & =\text { the percentage departure. } \\
\lambda & =\text { the observed thread length. } \\
\lambda_{0} & =\text { the average of the observed thread lengths. }
\end{aligned}
$$

Columns 7 and 8 of table 1 list the maximum positive and negative departures from the average diameter, and column 9 lists the average departure of the individual determinations from the average diameter.

The tubes studied were not all made by the same manufacturing process. The starting material in each case was tubing having an outside diameter of approximately $1 \frac{1}{4}$ in. Tubes 1 to 3 were drawn over steel mandrels through dies that reduced the diameter by about one-quarter at each step, until the inside diameter was about 0.09 in. Thereafter the reductions were accomplished without mandrels.

A second set of tubes (not listed in table 1) were obtained from a manufacturer who drew the tubes to the finish diameter over mandrels. It was found that the rolls used in loosening the tubing from the mandrels were not perfectly centered and therefore produced a periodic variation in the diameters, which rendered the tubes unuseable. The variations amounted to as much as \pm 5 percent. Attempts were made to eliminate these differences by successive drawing through external dies, with slight diameter reduction. After four stages, the variations were somewhat reduced, but the periodic character persisted and the tubes were abandoned. Tubes 8 to 12 , with heavier walls, were then supplied by the same manufacturer. In a lot of six tubes, only one was found to have unsatisfactory characteristics.

\section{Summary}

It has been found practical to apply the method of Fisher to the determination of flow constants for metallic capillary tubing and to study the uniformity of such tubing by X-ray photography of a mercury thread within the tube. Eight pieces of tubing were selected from a group of twelve, having a maximum deviation from the average diameter of 2.5 percent. Flow constants for these eight tubes were determined.

Washington, April 18, 1950.

\title{
Mass Spectra of Some Simple Isotopic Molecules
}

\author{
By Vernon H. Dibeler, Fred L. Mohler, Edmund J. Wells, Jr., and Robert M. Reese \\ The mass spectra of $\mathrm{H}_{2}, \mathrm{D}_{2}, \mathrm{~T}_{2}, \mathrm{HD}$, and $\mathrm{HT}$ have been measured with a Consolidated \\ mass spectrometer with 50 -volts ionizing voltage and with a constant magnetic field. The \\ following ratios of atom ions to molecule ions were observed: $\mathrm{H}^{+} / \mathrm{H}_{2}^{+}=0.0201, \mathrm{D}^{+} / \mathrm{D}_{2}^{+}=$ \\ $0.0096, \quad \mathrm{~T}^{+} / \mathrm{T}_{2}^{+}=0.0061, \quad \mathrm{H}^{+} / \mathrm{HD}^{+}=0.0096, \quad \mathrm{D}^{+} / \mathrm{HD}^{+}=0.0097, \quad \mathrm{H}^{+} / \mathrm{HT}^{+}=0.0085, \quad$ and \\ $\mathrm{T}^{+} / \mathrm{HT}^{+}=0.0068$. The ratios for $\mathrm{T}_{2}$ and $\mathrm{HT}$ were derived from spectra of two samples \\ containing 91 and 37 atomic percent of $\mathrm{T}$ in equilibrium with $\mathrm{H}$. Theoretical values for the \\ ratios were computed for ionization involving transition into the $\Sigma_{g}$ state of the molecule ion. \\ These values are lower than the observed ratios, because transitions to higher repulsive \\ states contribute to the observed values at 50 -volts ionizing voltage. \\ Mass spectra of $\mathrm{CO}$ and $\mathrm{CO}_{2}$ containing about 54 atom percent $\mathrm{C}^{13}$ were measured \\ under standard operating conditions. For $\mathrm{CO}$ the ratio $\mathrm{C}^{12+} / \mathrm{C}^{12} \mathrm{O}^{+}=0.0540$ and $\mathrm{C}^{13+} /-$ \\ $\mathrm{C}^{13} \mathrm{O}^{+}=0.0514$. For $\mathrm{CO}_{2}$, the ratios are $\mathrm{C}^{12} \mathrm{O}^{+} / \mathrm{C}^{12} \mathrm{O}_{2}^{+}=0.0868, \mathrm{C}^{13} \mathrm{O}^{+} / \mathrm{C}^{13} \mathrm{O}_{2}^{+}=0.0824$, \\ $\mathrm{C}^{12+} / \mathrm{C}^{12} \mathrm{O}^{+}=0.0564$, and $\mathrm{C}^{13}+/ \mathrm{C}^{13} \mathrm{O}_{2}^{+}=0.0542$. \\ A theory of the isotope effect in $\mathrm{CO}$ involving simplifying assumptions indicates that \\ the relative probability of producing $\mathrm{C}^{12}+$ is 3.5 percent greater than the probability of pro- \\ ducing $\mathrm{C}^{13+}$, as compared with an observed difference of 5 percent.
}

\section{Isotopic Hydrogen Molecules}

\section{Introduction}

Mass spectra of $\mathrm{H}_{2}$ and $\mathrm{D}_{2}$ have been investigated frequently [1], ${ }^{1}$ and a recent paper by Friedel and

${ }_{1}$ Figures in brackets indicate the literature references at the end of this paper.
Sharkey [2] gives the spectrum of HD. The present research was undertaken because of the opportunity to obtain some very pure HD and a sample of tritium of relatively good purity. Hydrogenic spectra are of interest because it is possible to compute theoretically from the Franck-Condon principle the relative probabilities of producing atom ions from the differ- 
ent isotopic molecules, and a comparison of theory and experiment gives information on the mechanism of dissociation. Stevenson [3] has carried out the theoretical computations for $\mathrm{H}_{2}$ and $\mathrm{D}_{2}$. Data on these molecules are also of practical importance in the analysis of isotopic mixtures.

\section{Experimental Procedure}

A $180^{\circ}$ Consolidated mass spectrometer was used, operated with a constant magnetic field requiring $3,800 \mathrm{v}$ to focus mass 1 and using an ionizing voltage of $50 \mathrm{v}$. Pumps were speeded up, and pressure in the ionization chamber was kept fairly low to maintain a high vacuum in the spectrometer. This is a necessary precaution [4] with hydrogen, but as a result the atom ion peaks are rather small for accurate measurement. There are no triatomic ions under these conditions.

Very pure $\mathrm{D}_{2}$ and $\mathrm{HD}$ were prepared by fractionation at liquid hydrogen temperatures by Fookson, et al. [5] of this Bureau. HD was fractionated from crude $\mathrm{HD}$ prepared by the reaction of $\mathrm{D}_{2} \mathrm{O}$ and lithium aluminum hydride [6]. The tritium was obtained from Argonne National Laboratory and was 91 percent of $\mathrm{T}$ and 9 percent of $\mathrm{H}$. It was separated from $\mathrm{He}^{3} 16$ days before the spectrum was measured. A small correction amounting to 0.16 percent was applied for $\mathrm{He}^{3}$ on the basis of a half-life of 12 years for tritium and the measured sensitivity (current per unit pressure) of $\mathrm{He}^{4}$.

Table 1 gives the experimental results under columns headed "Expt." Data for $\mathrm{H}_{2}$ and $\mathrm{D}_{2}$ are consistent with published results. Friedel and Sharkey [2] report for HD values of 0.82 percent for $\mathrm{H}^{+}$and 1.13 percent for $\mathrm{D}^{+}$. The value for $\mathrm{D}^{+}$of HD in table 1 is an upper limit assuming $\mathrm{H}_{2}^{+}$is zero. The value of 0.97 percent is the lowest value obtained in several experiments, but $\mathrm{H}_{2}^{+}$may contribute an amount of the order of 0.1 percent to mass 2 . In the tritium both $\mathrm{T}_{2}$ and $\mathrm{HT}$ are present and contribute to the mass 3 peak. The separate contributions were evaluated by obtaining the spectrum of the original sample containing 9 percent of $\mathrm{H}$, then adding hydrogen and equilibrating the mixture in contact with an incandescent filament to obtain a mixture of 67 percent of $\mathrm{H}$ and 33 percent of $\mathrm{T}$ and repeating the measurement. In the first spectrum $\mathrm{T}_{2}$ was large and $\mathrm{TH}$ small, and in the second spectrum the reverse was true. From the two spectra, values are derived for both $\mathrm{T}^{+} / \mathrm{T}_{2}^{+}$and $\mathrm{T}^{+} / \mathrm{TH}^{+}$.

Table 1 includes the sensitivity (current per unit pressure) for the molecule ions. They are nearly equal except for $T_{2}$, which is about 10 percent lower than the other values. This is not surprising, as the ion accelerating voltage is only a third as much for $\mathrm{T}_{2}$ as for $\mathrm{H}_{2}$.

\section{Theory}

The ratio of atom ions to molecule ions can be computed by means of the Franck-Condon principle for the case of a transition from the normal state of hydrogen to the stable $\Sigma_{g}$ state of the molecule ion.
TABLE 1. Mass spectra of hydrogen molecules

\begin{tabular}{|c|c|c|c|c|c|c|c|c|c|c|}
\hline$m / e$ & \multicolumn{2}{|c|}{$\mathrm{H}_{2}$} & \multicolumn{2}{|c|}{$\mathrm{HD}$} & \multicolumn{2}{|c|}{$\mathrm{D}_{2}$} & \multicolumn{2}{|c|}{ HT } & \multicolumn{2}{|c|}{$\mathrm{T}_{2}$} \\
\hline & 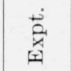 & $\begin{array}{l}\dot{\delta} \\
\stackrel{d}{E}\end{array}$ & $\underset{\vec{x}}{\vec{a}}$ & $\underset{\tilde{E}}{\tilde{E}}$ & $\underset{\vec{x}}{\vec{x}}$ & 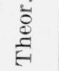 & $\underset{\vec{x}}{\vec{x}}$ & $\underset{\mathscr{E}}{\mathscr{g}}$ & $\underset{\vec{x}}{\vec{x}}$ & है \\
\hline - & $100^{2.01}$ & 1.9 & $\begin{array}{r}0.96 \\
.97\end{array}$ & $\begin{array}{r}0.7 \\
.7\end{array}$ & 0.96 & 0.8 & $\begin{array}{r}0.85 \\
\end{array}$ & 0.6 & & \\
\hline & & & 100 & & 100 & & .68 & 6 & 0.61 & 0.3 \\
\hline & & & & & & & & & 100 & $\cdots$ \\
\hline Sensitivity a & 20.0 & & 21. 2 & & 19.5 & & & . & 17.8 & - n \\
\hline
\end{tabular}

a Ion current per unit pressure in gas reservoir for the molecule ions in arbl. trary units.

Dissociation into an atom ion occurs if a vertical line from the normal state intersects the potential energy curve of the molecule ion at a point above the dissociation limit of the molecule ion. That is, the fraction of molecules with atoms inside a critical internuclear distance $r_{c}$ will dissociate on ionization and, for $\mathrm{H}_{2}$, about 2 percent of the atoms fall inside $r_{c}$ and give atom ions. The potential energy curves of the Franck-Condon diagram and $r_{c}$ remain unchanged in isotopic molecules. However, the radial distribution of atoms in the normal state is narrower for the heavy isotopes. This materially reduces the small fraction of atoms that fall inside $r_{c}$. Stevenson [3] has published computations for $\mathrm{H}_{2}$ and $\mathrm{D}_{2}$, and we have extended the computations to the other isotopic molecules. The values included in table 1 are subject to appreciable computational error, as they depend critically on the shape of the potential energy curves.

Experimental values are not exactly comparable with the theoretical values, for atom ions can also be produced by transitions to higher repulsive states of the hydrogen ion; namely, the $\Sigma_{u}$ state and the doubly ionized state. The most probable transition to a repulsive state requires about $10 \mathrm{v}$ in excess of the threshold for appearance of atom ions and results in ions of high kinetic energy. These ions are not collected efficiently by the mass spectrometer, and consequently they make only a small contribution to the atom ion peak. Hagstrum and Tate [7] have studied mass spectra of diatomic molecules and velocity distribution of the atom ions and have interpreted the results in terms of Franck-Condon diagrams. Their results for $\mathrm{H}_{2}$ show the magnitude of the contribution of the high velocity atom ions from repulsive states.

The contribution of atom ions from repulsive states accounts for the fact that experimental results for $50-\mathrm{v}$ electrons are always somewhat greater than the theoretical values. In the dissociation of HD the $\mathrm{H}^{+}$ion will have twice the kinetic energy of $\mathrm{D}^{+}$. In the mass spectrum obtained with a constant magnetic field the kinetic energy received from the electric field will also be twice as large for $\mathrm{H}^{+}$, so both ions should be collected with equal efficiency. Similarly $\mathrm{H}^{+}$and $\mathrm{T}^{+}$of $\mathrm{HT}$ should be measured with equal efficiency. The experimental observation that $\mathrm{T}^{+}$is less abundant than $\mathrm{H}^{+}$is unexplained. In other respects the experimental data seem quite consistent with theoretical predictions. 
A mixture of $\mathrm{D}_{2}$ and tritium was equilibrated in contact with an incandescent filament, but the spectrum of the mixture containing six isotopic molecules in appreciable amounts was too complicated to permit derivation of the $\mathrm{D}^{\prime} \mathrm{T}$ spectrum. Theoretical computations indicate that $\mathrm{D}^{+}$and $\mathrm{T}^{+}$will each be 0.35 percent of $\mathrm{D}^{\prime} \mathrm{T}^{+}$.

\section{Mass Spectra of $\mathrm{CO}$ and $\mathrm{CO}_{2}$}

\section{Introduction}

One would expect to find isotope effects in the mass spectra of molecules other than hydrogen, but the isotope effects will be much smaller when there is a relatively small difference in the mass of the isotopes involved. There is ample evidence for such effects both in mass spectra and in thermal dissociation. Dibeler, Mohler, and Reese have reported such effects in the spectrum of nitrogen containing 65 percent of $\mathrm{N}^{15}$ [8]. Beeck, et al. [9] have reported that the dissociation probabilities of $\mathrm{C}^{12}-\mathrm{C}^{12}$ and $\mathrm{C}^{12}-\mathrm{C}^{13}$ bonds of molecule ions formed from propane-1- $\mathrm{C}^{13}$ differ by about 20 percent, whereas Stevenson, et al. [10] find that in the thermal cracking of this molecule there is an 8-percent greater frequency of rupture of $\mathrm{C}^{12}-\mathrm{C}^{12}$ bonds than of $\mathrm{C}^{12}-\mathrm{C}^{13}$ bonds. Thermal decomposition of oxalic acid to give $\mathrm{CO}, \mathrm{CO}_{2}$, and $\mathrm{H}_{2} \mathrm{O}$ has been studied by Lindsay, McElcheran, and Thode [11], and on the basis of the distribution of $\mathrm{C}^{13}$ in $\mathrm{CO}$ and $\mathrm{CO}_{2}$ they concluded that the dissociation of a $\mathrm{C}^{12}-\mathrm{O}^{16}$ bond is approximately 3.5 percent more frequent than the dissociation of a $\mathrm{C}^{13}-\mathrm{O}^{16}$ bond.

\section{Experimental Procedure}

We have measured the relative abundance of the ions containing $\mathrm{C}^{12}$ and $\mathrm{C}^{13}$ in the mass spectrum of carbon monoxide and of carbon dioxide with high concentration of $\mathrm{C}^{13}$. Carbon dioxide was evolved in vacuum by the action of concentrated sulfuric acid on barium carbonate containing 54 atom percent of $\mathrm{C}^{13}$. A portion of the product was almost completely reduced to carbon monoxide over hot zinc according to the method of Bernstein and Taylor [12]. Traces of carbon dioxide were removed in a liquid nitrogen trap.

Mass spectra were obtained by using conventional techniques. The energy of the bombarding electrons was nominally $50 \mathrm{v}$, and the temperature of the ionization chamber was about $245^{\circ} \mathrm{C}$. Data reported here were measured at constant magnetic field and varying ion accelerating voltage. In the case of $\mathrm{CO}_{2}$, however, spectra were also obtained at constant ion accelerating voltage by varying the magnetic field. These spectra differ slightly in the ratios $\mathrm{CO}^{+} / \mathrm{CO}_{2}^{+}$and $\mathrm{C}^{+} / \mathrm{CO}_{2}^{+}$, but the relative amounts of isotopic ions were the same within the estimated experimental error.

\section{Results}

Table 2 gives the mass spectra of carbon monoxide and carbon dioxide containing 54 atom percent $\mathrm{C}^{13}$. Corrections have been made for the contributions of oxygen isotopes to the isotopic peaks. Columns 1 and 2 give the mass to charge ratio and the ion species for carbon monoxide. Column 3 gives the abundance of each ion relative to the most abundant ion, $m / e=29$. The ratio $\mathrm{C}^{12} / \mathrm{C}^{12} \mathrm{O}^{16}$ equals 0.0540 , whereas the ratio $\mathrm{C}^{13} / \mathrm{C}^{13} \mathrm{O}^{16}$ equals 0.0514 . The ratio of these two values, 1.05 , is a measure of the relative probability of dissociating a $\mathrm{C}^{12}-\mathrm{O}^{16}$ bond as compared with a $\mathrm{C}^{13}-\mathrm{O}^{16}$ bond in the $\mathrm{CO}$ molecule. TABLE 2. Mass spectra of $\mathrm{CO}$ and $\mathrm{CO}_{2}$ containing

[Correction has been made for oxygen isotopes]

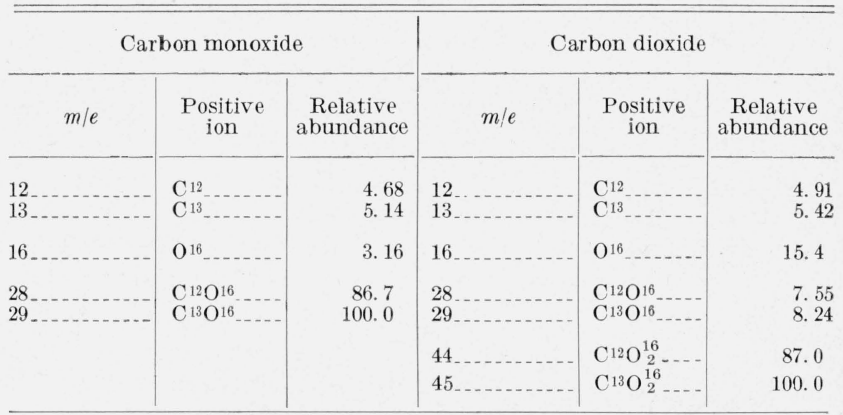

Columns 4, 5, and 6 of table 2 give the mass spectrum of carbon dioxide relative to the most abundant ion, $m / e=45$. For the dissociation of a single $\mathrm{C}-\mathrm{O}$ bond, the ratio $\mathrm{C}^{12} \mathrm{O}^{16} / \mathrm{C}^{12} \mathrm{O}_{2}^{16}$ equals 0.0868 , whereas the ratio $\mathrm{C}^{13} \mathrm{O}^{16} / \mathrm{C}^{13} \mathrm{O}_{2}^{16}$ equals 0.0824. Again, the ratio of these two values, 1.05, is a measure of the probability of dissociating a $\mathrm{C}^{12}-\mathrm{O}^{16}$ bond, as compared with a $\mathrm{C}^{13}-\mathrm{O}^{16}$ bond. For the dissociation of two $\mathrm{C}-\mathrm{O}$ bonds, the ratio $\mathrm{C}^{12} / \mathrm{C}^{12} \mathrm{O}_{2}^{16}$ equals 0.0564 , whereas the ratio $\mathrm{C}^{13} / \mathrm{C}^{13} \mathrm{O}_{2}^{16}$ is 0.0542 . Rather surprisingly the ratio of these values, 1.04, indicates that the dissociation of two $\mathrm{C}^{12}-\mathrm{O}^{16}$ bonds is only 4 percent more frequent than the dissociation of two $\mathrm{C}^{13}-\mathrm{O}^{16}$ bonds. Measurements made on a sample of carbon dioxide containing 4 atom percent of $\mathrm{C}^{14}$ gave similar, though less accurate, results for the relative probability of dissociating $\mathrm{C}^{12}-\mathrm{O}^{16}$ bonds and $\mathrm{C}^{14}-\mathrm{O}^{16}$ bonds. The results on the preferential dissociation of a $\mathrm{C}^{12}-\mathrm{O}^{16}$ bond compared with a $\mathrm{C}^{13}-\mathrm{O}^{16}$ bond in the ionization process are similar to the results of Lindsay, McElcheran, and Thode [11] on thermal dissociation of oxalic acid.

\section{Discussion}

Similar effects of isotopes on the dissociation probabilities of other molecules have been observed in this laboratory. From analysis of the mass spectrum of nitrogen [8] containing 65 atom percent of $\mathrm{N}^{15}$ it was found that an $\mathrm{N}^{14}-\mathrm{N}^{14}$ bond dissociates about 11 percent more frequently than an $\mathrm{N}^{15}-\mathrm{N}^{15}$ bond. The relative probability of dissociating an $\mathrm{N}^{14}-\mathrm{N}^{15}$ bond was less accurately determined, but the value is intermediate between the values for $\mathrm{N}_{2}^{14}$ and $\mathrm{N}_{2}^{15}$.

It is to be expected that isotope effects in $\mathrm{CO}$ and $\mathrm{N}_{2}$ can be explained in terms of the Franck-Condon 
principle, except for the difficulty that potential energy curves for the molecule ion states are not accurately known. D. P. Stevenson in an unpublished paper presented before the New Orleans meeting of mass spectrometer users in May 1950 pointed out that the isotope effect in $\mathrm{N}_{2}$ can be estimated without detailed knowledge of the upper potential energy curve. The observation that $\mathrm{N}^{+}$ is about 6.7 percent of $\mathrm{N}_{2}^{14+}$ indicates that in the radial distribution of atoms in the normal state, 6.7 percent of the atoms fall inside the critical internuclear distance for dissociation in the ionized state. From the known distribution of atoms in the normal state, the critical internuclear distance can be computed. In $\mathrm{N}_{2}^{15}$ the distribution of atoms will be reduced by an amount that will result in a 7 percent reduction of the fraction inside the critical internuclear distance. This is considered in substantial agreement with the observed difference of 11 percent.

This interpretation is supported by the research of Hagstrum and Tate [7] on the velocity distribution of atom ions as related to the Franck-Condon diagrams. The velocity distribution of $\mathrm{N}^{+}$ions indicates that dissociation comes primarily from a process of the type postulated by Stevenson. This is also true of $\mathrm{C}^{+}$from $\mathrm{CO}$. On the basis that 5.4 percent of $\mathrm{C}$ atoms of $\mathrm{C}^{12} \mathrm{O}^{16}$ fall inside the critical internuclear distance, it is estimated that in $\mathrm{C}^{13} \mathrm{O}^{16}$ there will be a 3.5 -percent reduction in the fraction inside the critical distance. The observed difference was 5 percent. Exact agreement is not expected, for the theory assumes that a single transition process gives rise to $\mathrm{C}^{+}$. It is known that at least two transitions give $\mathrm{C}^{+}$; one or more giving $\mathrm{C}^{+}$and $\mathrm{O}$ and one or more giving $\mathrm{C}^{+}$and $\mathrm{O}^{-}$.

\section{Conclusion}

Isotope effects in the diatomic molecules, hydrogen, nitrogen, and $\mathrm{C}^{+}$of $\mathrm{CO}$ seem to be accounted for by the Franck-Condon principle and the fact that the radial distribution of atoms in the normal state depends on the mass of the isotopes. In these molecules a small fraction of the atoms in the normal state falls inside the critical internuclear distance for dissociation in the ionized state, and this condition leads to a relatively large isotope effect. The research of
Hagstrum and Tate [6] on the ionization of diatomic molecules indicates that production of $\mathrm{O}^{+}$from $\mathrm{O}_{2}$ and of $\mathrm{N}^{+}$from $\mathrm{NO}$ will be similar in this respect to $\mathrm{N}_{2}$. However, for the transitions giving $\mathrm{O}^{+}$from $\mathrm{CO}$ and $\mathrm{O}^{+}$from $\mathrm{NO}$, roughly half and three quarters respectively of the atoms fall inside the critical radius and the isotope effect would presumably be much less. One would not expect the relative amount of $\mathrm{O}_{16}{ }^{+}$from the isotopic mixture of $\mathrm{C}^{12} \mathrm{O}^{16}$ and $\mathrm{C}^{13} \mathrm{O}^{16}$ of table 2 to be significantly different from normal $\mathrm{CO}$, and this is experimentally observed.

Although similar effects may be expected in polyatomic molecules, it is not feasible to predict quantitatively the isotope effects in $\mathrm{CO}_{2}$ or more complicated molecules. It may be coincidental that production of $\mathrm{C}^{+}$and $\mathrm{CO}^{+}$from $\mathrm{CO}_{2}$ show almost the same isotope effect as $\mathrm{C}^{+}$from $\mathrm{CO}$. The theory of diatomic molecules indicates that each dissociation process will have a characteristic isotope effect, and values of zero or even negative values are not excluded. ${ }^{2}$

\section{References}

[1] N. Bauer and J. Y. Beach, J. Chem. Phys. 15, 150 (1947).

[2] R. A. Friedel and A. G. Sharkey, Jr., J. Chem. Phys. 17, 584 (1947).

[3] D. P. Stevenson, J. Chem. Phys, 15, 409 (1947).

[4] R. E. Honig, J. Chem. Phys. 16, 837 (1948).

[5] A. Fookson, P. Pomerantz, and E. H. Rich, Science, in press.

[6] I. Wender, R. A. Friedel, and M. Orchin, J. Am. Chem. Soc., 71, 140 (1949).

[7] H. D. Hagstrum and J. T. Tate, Phys. Rev. 59, 354 (1941).

[8] V. H. Dibeler, F. L. Mohler, and R. M. Reese, J. Chem. Phys. 18, 156 (1950).

[9] O. Beeck, J. W. Otvos, D. P. Stevenson, and C. D. Wagner, J. Chem. Phys. 16, 255 (1948).

[10] D. P. Stevenson, C. D. Wagner, O. Beeck, and J. W. Otvos, J. Chem. Phys. 16, 993 (1948).

[11] J. G. Lindsay, D. E. MeElcheran, and H. G. Thode, J. Chem. Phys. 17, 589 (1949).

[12] R. B. Bernstein and T. I. Taylor, Science 106, 498 (1949).

[13] O. Schaeffer and J. Hastings, Quarterly Progress Report, p. 31 (Brookhaven National Labratory, Mar. 31, $1950)$.

Washington, June 21, 1950.

${ }^{2}$ A progress report by O. Schaeffer and J. Hastings of the Brookhaven National Laboratory [13] on mass spectra of $\mathrm{H}_{2}, \mathrm{D}_{2}$, and $\mathrm{T}_{2}$ has appeared since this paper was written. They report ratios of atom ions to molecule lons obtained from ionization by electrons of 30 electron volts, and values are considerably smaller ionization by electrons of 30 electron volts, and values are considerably smaller their results are comparable with ours. 